\title{
EXTERNAL IMBALANCES, VALUATION ADJUSTMENTS AND REAL EXCHANGE RATE: EVIDENCE OF PREDICTABILITY IN AN EMERGING ECONOMY*
}

\author{
DESBALANCES EXTERNOS, AJUSTES DE VALORACION Y TIPO DE \\ CAMBIO REAL: EVIDENCIA SOBRE PREDICTIBILIDAD EN UNA \\ ECONOMIA EMERGENTE
}

\section{PABLO PINCHEIRA}

Central Bank of Chile

JORGE SELAIVE

Banco de Crédito e Inversiones

\begin{abstract}
In this paper we provide evidence of exchange rate predictability for a selected emerging market economy (EME) at intermediate horizons, arguably, the most relevant for policy purposes. This is important because the existing literature on exchange rate predictability has mainly focused on developed economies, leaving relatively unexplored the question for EME. By making use of a unique quarterly database of external assets and liabilities for Chile, we show that a measure of external imbalances is able to predict the real exchange rate over horizons of up to two years. Robust out-of-sample evidence on predictability reflects the fact that the external balance's importance to the exchange rate has risen in recent years and/or the precision of parameter estimates rises as sample size grows larger. When we break down our measure for external imbalances into its three component ratios (exports to imports, exports to assets, and assets to liabilities), we find that predictability is mainly driven by the last two. Our results suggest that researchers and policymakers should pay attention to external imbalances to understand the future dynamics of the real exchange rate.
\end{abstract}

Keywords: Real exchange rate, net foreign assets, valuation adjustments, forecasting evaluation.

JEL Classification: F 21, F31, F47.

* We thank Rodrigo Valdés, Barbara Rossi and Kenneth West for comments on an earlier version of this paper. We also thank Andrea Bentancor and Gustavo Leyva for his research assistance. All remaining errors are ours. Correspondence: Agustinas 1180. Santiago-Chile. Tel: (562) 670-2000, Fax: (562) 670-2836. E-mail: ppinchei@bcentral.cl; jselaiv@bci.cl. The views expressed in this paper do not necessarily represent those of the Central Bank of Chile. 


\section{Resumen}

En este trabajo evaluamos la habilidad de una medida de desbalance externo, que combina el canal de comercio y el financiero, para predecir el tipo de cambio real en Chile. Utilizando una base de datos que contiene los activos y pasivos externos en frecuencia trimestral desde 1983 a 2005, y empleando recientes tests de habilidad predictiva fuera de muestra, mostramos que nuestra medida de desbalance externo es capaz de predecir el tipo de cambio real en horizontes de hasta dos años. La evidencia de predictibilidad tiende a ser más fuerte en la medida que se amplía la ventana de estimación de los parámetros. Esto es probablemente producto de la mayor importancia relativa del desbalance externo en la dinámica del tipo de cambio en los últimos años, o de la creciente precisión en la estimación de los parámetros al aumentar el tamaño muestral. Cuando evaluamos los tres componentes de la medida de desbalance externo: razón exportaciones a importaciones, exportaciones a activos y activos a pasivos, encontramos que la capacidad predictiva fuera de muestra es principalmente explicada por los dos últimos cuocientes.

Palabras Clave: Tipo de cambio real, activos externos netos, cambio de valoración de activos, evaluación de proyecciones.

Clasificación JEL: F21, F31, F47.

\section{INTRODUCTION}

The current debate on exchange rate predictability is about how well models can perform at intermediate horizons, arguably the most relevant for policy purposes, see for instance Rogoff and Stavrakeva (2008). Up until now, the main finding in the literature is that it is very difficult to find empirical models that work well on a consistent and robust basis, even against the apparently weak benchmark of the random-walk model, as Meese and Rogoff (1983a, 1983b) first demonstrated.

Researchers and policymakers have continued to investigate how new models and new out-of-sample tests may help to detect exchange rate predictability at intermediate horizons. Clarida and Taylor (1997), Clarida et al. (2003), Clark and West (2006, 2007) and McCraken (2007), among many others, have made important contributions in this regard. Despite these contributions, the martingale hypothesis has also found some support in recent research. For instance, Engel, Mark and West (2007) show that traditional models suggest a quasi-random walk behavior in foreign currencies. This finding, along with results in Rogoff and Stavrakeva (2008), reinforces the idea about exchange rate unpredictability. 
Most of the literature on exchange rate predictability has focused on major floating currencies and not on emerging market currencies, where interest and inflation differentials are often much larger than in developed economies. Besides these differences, several EME are major commodity exporters, which may also have a great impact on their currencies. Actually, Chen and Rogoff (2003) find for a couple of developed countries that the international price of their commodity exports is strongly related to their real exchange rates. They also suggest that this result might still hold true for commodity-exporting EME as they approach towards a floating exchange rate regime, as it happened in Chile by the end of the last century.

Recent research has found that current account deficits and the associated net financial inflows are not the only factors influencing changes in a country's International Investment Position (IIP). Specifically, changes in asset prices and exchange rates affect the stock of assets and liabilities making up the IIP (Lane and Milesi-Ferreti, LMF, 2005). In recent years, the literature has documented the growing importance of these factors in emerging economies. As the volumes of gross assets and liabilities have soared, asset prices and exchange rate fluctuations have generated larger capital gains and losses. These changes in asset and liability stocks, associated with unrealized capital gains and triggered by changes in asset prices and exchange rates, have been referred to as valuation adjustments.

Gourinchas and Rey (2007) have shown that "multilateral" real dollar exchange rates are well predicted by a measure of external imbalances that takes into account the trade and financial channels involved in the external adjustment ${ }^{1}$. Insight into the linkage between external assets and the real exchange rate can be found in the so-called "transfer problem", whose central prediction states that the wealth effects and international investment income flows associated with non-zero net foreign asset positions require some degree of real exchange-rate adjustment in the long run. Although the short-run comovement between net foreign assets and the real exchange rate depends on the underlying shock, several approaches predict that real appreciations should be associated with accumulation of net foreign assets in the long run. Countries with large external liabilities must run large trade surpluses to service them, and achieving these requires depreciation of the real exchange rate (Lane and Milesi-Ferretti, 2004).

Gourinchas and Rey find that over a horizon of a single quarter, they were able to explain $11 \%$ of exchange rate variance, rising to $44 \%$ for one and $61 \%$ for three years ahead. Specifically, they statistically outperformed a random walk in an out-ofsample exercise over all horizons from one to 12 quarters ahead, providing relevant evidence that overturned results from Meese and Rogoff (1983a, 1983b). In addition to the traditional trade channel, the financial channel is naturally implicated by an intertemporal budget constraint allowing for valuation changes in foreign assets and liabilities. As mentioned above, the change in a country's net foreign asset position

1 Gourinchas and Rey's approach builds on Lettau and Ludvigson (2001) on the implication of the consumption-wealth ratio for predicting future equity returns. Similarly, Selaive and Tuesta (2005) show theoretical reasons to expect exchange rate predictability using this ratio, and they present forecasting evidence in that direction. 
need not equal its current account, because the current account does not track unrealized capital gains arising from local and foreign asset prices and currency movements. These valuation effects are equal to the capital gain on the net foreign asset portfolio (total net return minus income), dividends and earnings distributed ${ }^{2}$. Gourinchas and Rey provide a detailed account of the US' foreign investment position. They report yields across different types of assets and liabilities, identify the impact of dollar depreciation on yields, and discuss the channels by which the exchange rate facilitates adjustment $^{3}$.

Following this line of research, in this paper we examine the ability of a measure for external imbalances and its components to predict a selected EME`s real exchange rate (RER) at intermediate and long horizons. We have chosen the case of the Chilean economy since data on external assets and liabilities at quarterly frequency, and for a long period of time is only available for that economy. In particular, we use a unique database offering quarterly data for Chile from 1983 to 2005. This database, especially prepared for Chile, differs from LMF's in the frequency of components of its external position ${ }^{4}$.

We find that a measure for external imbalances, which combines the trade and the financial channels, is useful to predict Chile's RER over horizons of up to two years. We also find promising out-of-sample predictability and systematic evidence that predictability increases with the size of the window used to estimate model parameters. This may reflect the fact that the economy's external balance has become more relevant to exchange rate dynamics in recent years and/or parameter estimates may become more precise as the size of the estimation window increases. When we break down our measure of external imbalances into its three component ratios (exports to imports, exports to assets, and assets to liabilities), we find that out-of-sample predictability is mainly driven by the last two.

The evidence presented in this paper supports the view that external imbalances are helpful for predicting the RER not only in developed but also EMEs, at intermediate horizons. More importantly, our results suggest that researchers and policymakers should pay more attention to external imbalances to understand the future dynamics of the real exchange rate in developing economies.

The paper is organized as follows. The next section explains the measure for external imbalances and the data used in the forecasting exercises. The third and fourth sections present the forecasting exercises, and the last section offers conclusions.

2 See De Gregorio (2005) for the implications of valuation adjustments in an emerging market economy and related policy implications.

3 Tille (2003) explores the relative importance of asset price changes and exchange rate changes for valuation adjustments. He finds that between 1999 and 2001 valuation adjustments were responsible for $37 \%$ of the worsening of the U.S NIIP.

4 Pistelli, Selaive and Valdés (2005) make use of LMF's database to explore the role of assets, liabilities and valuation adjustments in sudden stops, currency crises and speculative attacks. 


\section{A MEASURE FOR EXTERNAL IMBALANCE THAT INCLUDES VALUATION ADJUSTMENTS}

Gourinchas and Rey (2007), Alquist and Chinn (2006) and LMF (2005) all propose a modeling approach that combines trade and valuation channels. They derive the following expression for net portfolio return, "ret", which combines market- and exchange-rate-induced valuation effects:

$$
r e t_{\mathrm{t}}=\alpha+\beta n x a_{\mathrm{t}-1}+\mathrm{Z}_{\mathrm{t}-1} \Theta+\varepsilon_{t}
$$

where $\mathrm{Z}$ is a set of control variables, and

$$
n x a=\left|\frac{\mu_{m}}{\mu_{x}}\right| x m+\left|\frac{\mu_{l}}{\mu_{x}}\right| a l+\frac{1}{\left|\mu_{x}\right|} x a
$$

where the $\mu$ 's are normalized weights; $x m$ is net exports' deviation from trend; $a l$ is net assets' deviation from trend, and $x a$ is exports-to-assets' deviation from trend. These variables are estimated as the residuals of a cointegrating relationship between exports and imports $(x m)$, assets and liabilities (al) and exports and assets $(x a)$. Gourinchas and Rey use Stock and Watson's (1993) dynamic least square technique and estimate single OLS regressions that include leads and lags for changes in the dependent variable.

The normalized weights $\mu_{x}$ and $\mu_{m}$ represent the relative importance of exports and imports in the steady state's trade balance. $\mu_{a}$ and $\mu_{l}$ have similar definitions for assets and liabilities in the net external position. Based on stationarity assumptions for the ratio of assets, liabilities, export and imports to household wealth in the US, Gourinchas and Rey define:

$$
\begin{aligned}
& \mu_{x}=\frac{\mu_{x w}}{\mu_{x w}-\mu_{m w}} ; \mu_{x}=\mu_{m}+1, \\
& \text { and } \\
& \mu_{a}=\frac{\mu_{a w}}{\mu_{a w}-\mu_{l w}} ; \mu_{a}=\mu_{l}+1,
\end{aligned}
$$

where $\mu_{i w}$ is the ratio of $\mathrm{i}=$ exports, imports, assets, liabilities to household wealth.

In this context, nxa can be interpreted as: "approximately the percentage increase in exports necessary to restore external balance (i.e., compensate for the deviation from trend of the net exports to net foreign asset ratio)" (Gourinchas and Rey, 2007).

Based on Gourinchas and Rey's approach, we construct a variable similar to $n x a$ to carry out inference on predictability for the RER over several horizons. To do so, we used a database that compiles and recalculates stocks and flows of the main components of the IIP for Chile (1983-2005) on a quarterly basis. 
Figure 1 plots the series used as building blocks in our approach. It illustrates the tendency for assets and liabilities to rise in line with the associated import and export flows. This reveals Chile's growing financial integration into the world economy in recent decades. In fact, when measured over GDP, external assets rose from $48 \%$ in 1990 to $80 \%$ in 2005, while external liabilities reached 1.2 times GDP in 2005.

\section{FIGURE 1}

IMPORTS, EXPORTS, ASSETS AND LIABILITIES: 1983.1-2005.4

(Figures in Logs US\$ million)

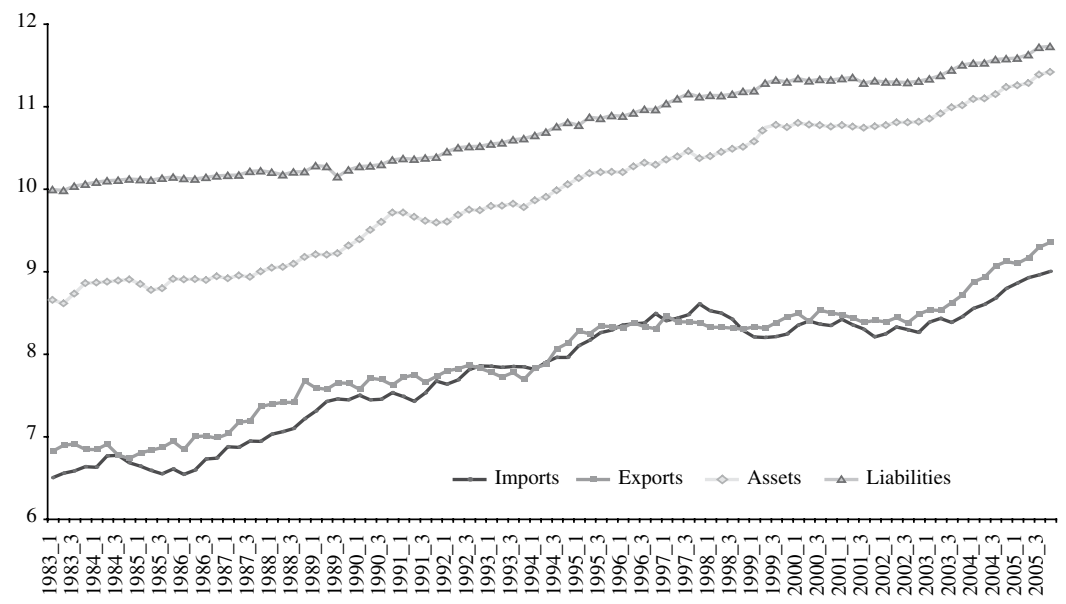

Source: Authors' calculations.

Calibrating the normalized weights used by Gourinchas and Rey is not straightforward in the case of Chile. There is no time series information on household wealth, while relying on average shares for exports, imports, gross foreign assets and liabilities over other denominators may be either arbitrary or reflect the problem of estimating steady state variables using too short a period ${ }^{5}$. We therefore used a statistically-based method, combining the vectors $x m, a l$ and $x a$, using weights associated with their principal component. By doing so, we acknowledge that the economic interpretation of this variable may differ from that given by Gourinchas and Rey6. follows,

Specifically, we define the NXAP variable and its real time variant NXAPR ${ }^{\mathrm{R}}$, as

5 Pan (2006) uses gross national income instead of household wealth.

6 We chose principal component analysis as a standard and well known procedure that allows us to combine series eliminating capricious alternatives. By doing so, our work can be reproduced by other researcher and more importantly, applied to other countries where the restrictions to perform G\&R' identical procedure are the same as in Chile. 


$$
\begin{aligned}
& N X A P=\lambda_{1} x m+\lambda_{2} l a+\lambda_{3} x a \\
& N X A P^{R}=\lambda_{1}^{R} x m^{R}+\lambda_{2}^{R} l a^{R}+\lambda_{3}^{R} x a^{R}
\end{aligned}
$$

where the $\lambda$ s correspond to the coefficients associated with the principal components of vectors $x m$, $l a$ and $x a^{7}$. The difference between NXAP and NXAPR is given only by the definition of the information set at the moment of prediction: $\mathrm{NXAP}^{\mathrm{R}}$ is a quasi real time variable, meaning that it is built using estimates for the required cointegrating relationships and principal component weights, based on information available at the moment of prediction. NXAP is built in the same fashion as NXAPR but using full sample information to estimate the required cointegrating relationships and principal component weights. Predictive exercises with NXAPR are called out-of-sample, whereas exercises with NXAP are called pseudo out-of-sample 8 .

Figure 2 shows Chile's real effective exchange rate and our estimates for the three vectors $x m$, la and $x a$. The three series comove with the RER, yet show higher variability ${ }^{9}$.

\section{FIGURE 2}

\section{RESIDUAL COINTEGRATING VECTORS AND RER}

(estimated with full sample, 1983.I-2005.IV)

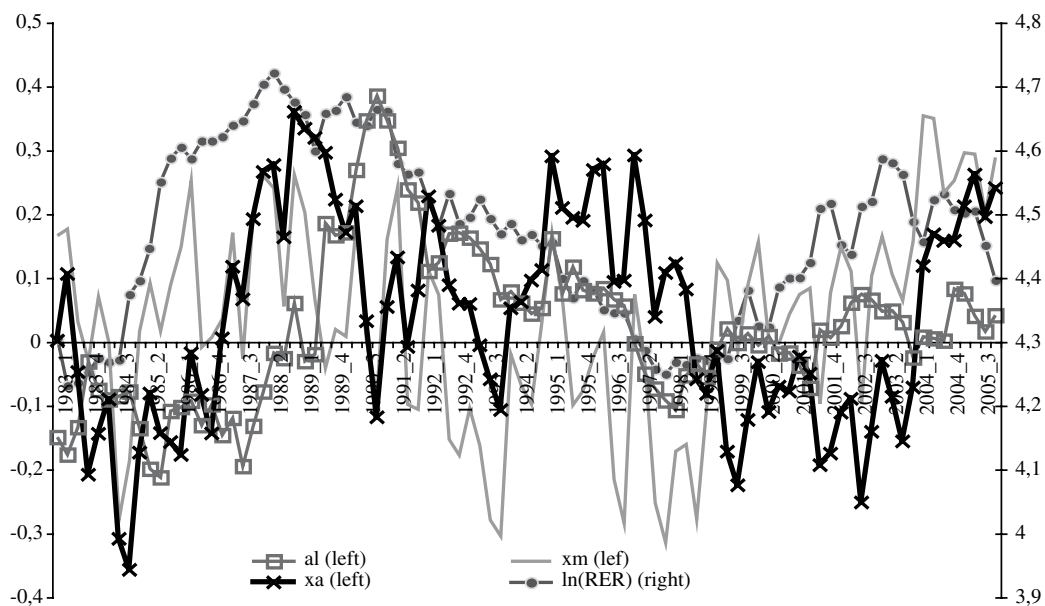

Source: Authors' calculations and Gourinchas and Rey (2007).

7 Principal components analysis has been used extensively in the financial and forecasting literature. See Flury (1988) and Stock and Watson (2002).

8 Unfortunately, we do not have real time vintages for variables, so we work with revised data.

9 Effective Real Exchange Rate is defined as domestic relative to foreign prices. We reject the null of a unit root for all estimated residuals of the cointegrating relationships at a $10 \%$ percent significance level, which supports our assumption of stationarity for these residuals. 
We also evaluate each $\mathrm{NXAP}^{\mathrm{R}}$ component's ability to predict the real effective exchange rate in Chile. This is done to identify the vectors driving the predictive ability of NXAP and NXAPR ${ }^{\mathrm{P}}$ Pan (2006) examines the role of the trade and financial channels separately, associating the predictive ability of $\mathrm{xm}$ to the former.

In a nutshell, we have a measure for external imbalances that we have labeled NXAP, derived as in Gourinchas and Rey in combination with a principal components analysis. In the next section, we evaluate this external imbalance measure's ability, and that of its components, to predict changes in Chile's RER.

\section{ECONOMETRIC SETUP}

We use an econometric setup based on Mark (1995) and very similar to that in Gourinchas and Rey (2007) and Clark and West (2006, 2007).

In our forecasting exercise, we compare how well our measure for external imbalances predicts RER returns over different horizons. We compare its predictive ability to three simple benchmarks: A driftless random walk, a random walk with drift and an AR(1) with drift. We also evaluate the measure components' ability to forecast Chile's RER. Expressed more formally, we have

$$
\begin{aligned}
& H_{A}: \operatorname{RERR}_{t+k}=\alpha_{k}+\beta_{k} x_{t}+\varepsilon_{t, t+k} \\
& H_{01}: \operatorname{RERR}_{t+k}=\varepsilon_{1 t+1, t+k} \\
& H_{02}: \operatorname{RERR}_{t+k}=\alpha_{k}+\varepsilon_{2 t+1, t+k} \\
& H_{03}: \operatorname{RERR}_{t+k}=\lambda_{k}+\gamma \operatorname{RERR}_{t}+\varepsilon_{3 t+1, t+k}
\end{aligned}
$$

where $R E R R_{t}$ represents the quarterly change in the logarithm of Chile's RER at time $t, \varepsilon_{i t+1, t+k}, i=1, . .3$ and $\varepsilon_{t+1, t+k}$ represents random perturbations uncorrelated with information available prior to time $t$, while $x_{t}$ represents a predictor.

Initially we have $T+2=92$ observations of the quarterly RER from 1983Q1 until 2005Q4. We drop one observation to evaluate predictability against an AR(1) model, so we end up with 91 observations. We evaluate predictability of RER returns over eight forecasting horizons, one to eight quarters ahead. The RER returns series $k$ step ahead contains $T+1-k$ observations. We estimate equations (4), (6) and (7) by rolling ${ }^{10}$ OLS, so we split the full sample into an estimation window of size R-k and a predictive window of size $T+2-k-R$.

10 Out-of-sample exercises usually update parameter estimates according to some variation of three major updating schemes: fixed, rolling or recursive. We use only the rolling scheme, because it is appropriate when working with time series with potential breaks, and because in the tests due to Clark and West parameter uncertainty is allowed to persist asymptotically. 
We carry out exercises of out-of-sample inference about predictive ability comparing model (4) to models (5), (6) and (7) ${ }^{11}$. Regardless of the criticisms of out-of-sample analyses, we consider these more appropriate to evaluate predictive ability in this particular application. This is partly because we want to compare our results with others included in the relevant literature, and partly because they better reflect the difficulty faced by a policy maker confronted with a real-time forecasting task.

When comparing models (4) and (7) we apply the traditional asymptotically normal test, developed by West (1996) and Diebold and Mariano (1995) with quadratic $\operatorname{loss}^{12}$. When comparing models (4-6) we notice that models (5) and (6) are nested in model (4), so this test's asymptotic normality no longer holds (see McCraken, 2007). Instead, we rely on two out-of sample tests recently developed by Clark and West (2006, 2007), which are appropriate in nested environments. The first test, called Mean Squared Prediction Error-Adjusted (MSPE-Adj) evaluates the predictive ability of the alternative model (4) against the driftless random walk in model (5) ${ }^{13}$. This test is asymptotically normal. To compare models (4) and (6), we use a variant of the MSPE-Adj test developed by Clark and West (2007). The distribution of this statistic under the null is shown to be well approximated by a normal distribution ${ }^{14}$.

We are aware that out-of-sample analyses may be too stringent to evaluate predictive ability with sample sizes typically available for countries like Chile. We therefore complement our out-of-sample (OOS) results with pseudo out-of-sample (POOS) results. The difference between these two sets of results relies in the construction of the variables used for prediction. Our OOS analyses consider prediction using quasi real time variants of the variables $\left(\mathrm{NXAP}^{\mathrm{R}}, x m^{R}, x a^{R}\right.$ and $\left.a l^{R}\right)$. Instead, our POOS analyses consider prediction only with NXAP, $x m, x a$ and $a l$, variables which include information from the whole sample.

11 Evaluation of predictive ability is usually carried out using two different approaches: in-sample and out-of-sample. Both approaches have advantages and disadvantages. For instance, in-sample analyses have the advantage of using all available observations for estimating unknown population parameters. In contrast, out-of-sample analyses split the available data into estimation and predictive windows. Fewer observations are of no help when attempting to get precise estimates of parameters in stationary environments. In fact, Inoue and Kilian (2004) argue that splitting the available sample into two different windows may reduce the power of out-of-sample tests compared to in-sample tests. The latter tests, however, are considered more reliable to deal with data mining-induced overfitting problems, as mentioned by Clark (2004).

12 The "asymptotic irrelevance" discussed by West (1996) allows us to rely on standard normal critical values, without further corrections due to parameter uncertainty.

13 Pincheira (2006) offers a useful interpretation of this test, showing that the rejection of the null model via the MSPE -Adjusted test implies the existence of a deterministic shrinkage factor for which the alternative model will display lower mean squared prediction error.

14 Note that we are interested in a one-sided test because if the alternative model is the correct model, the core statistics in the tests developed by Clark and West should be positive. Similarly, when comparing model (3) to model (6) via the Diebold and Mariano statistic, we expect the true model to display lower out-of-sample mean squared prediction error. Finally, estimates of the variance of the test statistics are computed with HAC estimation, according to Newey and West $(1987,1994)$. 


\section{EVALUATING PREDICTIVE ABILITY}

As mentioned before, we show results for our measure of external imbalances (NXAP) and its three components $x m, x a$ and $a l$. We also use a quasi real time variant of the variables that we denote by NXAPR $, x m^{R}, x a^{R}$ and $a l^{R}$. We use each of these four vectors to estimate model (4). We then compare these variables' predictive ability using the three benchmarks given by models 5-7. For each version of model (4) we engage in four empirical exercises. First, we assume that the number of observations used for the first estimation (R-k) is set at 65-k. Then we compute our statistics and analyze whether the tests are able to reject the three proposed null models at different significance levels.

Second, we analyze how robust the results from the first empirical exercise remain if we change the size of the estimation window. We carry out eleven forecast evaluations moving $\mathrm{R}$ from 65 to 75 and record the percentage of rejections at the $10 \%$ significance level.

Finally we repeat steps 1 and 2 assuming that the number of observations used for the first estimation (R-k) is set at 35-k, and then, as a robustness check, we move $\mathrm{R}$ from 35 to 45 to record the percentage of rejections at the $10 \%$ significance level.

We set the estimation window size at $\mathrm{R}-\mathrm{k}=65-\mathrm{k}$ and $\mathrm{R}-\mathrm{k}=35-\mathrm{k}$ mainly because these numbers represent roughly one- and two-thirds of the sample, respectively. In fact, the average estimation window for all the horizons has about 60 observations when $\mathrm{R}$ is set to 65 , and 30 observations when $\mathrm{R}$ is set to 35 . For brevity's sake, we only provide tables for the exercises with $\mathrm{R}$ set at 65 and 35 . Tables corresponding to the robustness checks are available upon request.

In the next two subsections we present tables with our forecasting evaluations. Figures reported in the tables correspond to t-type statistics from the tests by West (1996) and Diebold and Mariano (1995). We also present the t-type statistics from Clark and West tests.

\section{IV.1. Pseudo Out-of-Sample Exercise (POOS)}

In this subsection, we present forecasting results from a POOS exercise evaluating whether the NXAP variable and its individual components can predict RER returns over several horizons. Remember this exercise is called POOS because the cointegrating relationships and the principal component coefficients are obtained using the full sample available. In the tables, Panel 1 shows t-type statistics when the estimation window is set to $\mathrm{R}-\mathrm{k}=65-\mathrm{k}$, while Panel 2 shows these statistics when the estimation window is set to $R-k=35-k$.

Results in Table 1's Panel 1 show statistically significant evidence of predictability for horizons beyond two quarters ahead. Over these horizons, our measure of external imbalances outperforms the driftless random walk and the random walk with drift at the $10 \%, 5 \%$ or $1 \%$ significance levels. Our model also outperforms the AR(1) over the same horizons at a $10 \%$ significance level, at least.

Table 1's Panel 2 shows weaker results. Remember that the difference between panels 1 and 2 is that Panel 2 uses an estimation window that is about a half the size 


\section{TABLE 1}

PSEUDO OUT-OF-SAMPLE FORECAST EVALUATION OF CHANGES IN CHILE'S RER EXTERNAL IMBALANCES BASED ON GOURINCHAS AND REY'S VARIABLE (NXAP)

\begin{tabular}{|c|c|c|c|c|c|c|c|c|}
\hline (1) & (2) & (3) & (4) & (5) & (6) & (7) & (8) & (9) \\
\hline \multicolumn{9}{|c|}{$\begin{array}{l}\text { Panel 1: Estimation Window of Size: R-k=65-k } \\
\text { Predictive Horizon in Quarters }\end{array}$} \\
\hline Benchmark & 1 & 2 & 3 & 4 & 5 & 6 & 7 & 8 \\
\hline RW & 1.03 & 0.88 & $1.70 * *$ & $2.63^{* * *}$ & $2.26 * *$ & $2.28 * *$ & $2.41 * * *$ & $1.59 *$ \\
\hline RW-drift & 0.96 & 0.90 & $1.77 * *$ & $2.86 * * *$ & $2.63 * * *$ & $2.88 * * *$ & $3.21 * * *$ & $2.46 * * *$ \\
\hline $\mathrm{AR}(1)$ & 0.36 & 0.64 & $1.45^{*}$ & $2.07 * *$ & $1.86^{* *}$ & $2.03 * *$ & $2.04 * *$ & $1.51^{*}$ \\
\hline \multicolumn{9}{|c|}{ Panel 2: Estimation Window of Size: $\mathrm{R}-\mathrm{k}=35-\mathrm{k}$} \\
\hline Benchmark & 1 & 2 & 3 & 4 & 5 & 6 & 7 & 8 \\
\hline RW & -0.39 & -0.95 & -0.29 & 0.27 & -0.18 & -0.59 & -0.85 & -1.15 \\
\hline RW-drift & 0.83 & 0.16 & 1.24 & $1.94 * *$ & $1.82 * *$ & $1.52 *$ & $1.39 *$ & 0.99 \\
\hline $\mathrm{AR}(1)$ & 0.60 & 0.45 & 0.44 & 1.20 & $1.51^{*}$ & 0.55 & 0.23 & 0.42 \\
\hline
\end{tabular}

Notes: $*$ Rejection at $10 \%, * *$ Rejection at $5 \%, * * *$ Rejection at $1 \%$.

Pseudo out-of-sample means that the predictor is computed with information from the full sample. We consider three different null models for changes of the RER: a driftless random walk, a random walk with drift and an $\mathrm{AR}(1)$.

Alternative model is: $\ln \left(R E R \_t+k\right)-\ln \left(R E R \_t\right)=a+b * \ln \left(Z \_t\right)+u \_t$.

$\mathrm{Z}$ is a variable capturing external imbalances (NAXP), $\mathrm{k}$ denotes the predictive horizon.

Updating scheme of the parameter estimates is done via rolling OLS.

Panel 1 considers a rolling window of size $\mathrm{R}=65-\mathrm{k}$ for estimation of the parameters. Panel 2 considers $\mathrm{R}=35-\mathrm{k}$.

Total number of observations is $91-\mathrm{k}$.

We report t-type statistics from tests by Diebold and Mariano (1995) and West (1996), and Clark and West $(2006,2007)$.

HAC estimation is computed according to Newey and West (1987) with optimal lag selection based upon Newey and West (1994).

Quarterly data from 1983:1 to 2005:4.

Source: Author's calculations.

used in Panel 1. For this size of the estimation window, our model does not outperform a driftless random walk over any horizon. We found statistically significant evidence of predictability, however, when we compared our external imbalance measure to a random walk with drift. In this case, our model forecasts better within a range of four to seven quarters ahead. Finally, our model only outperforms an AR(1) with statistical significance for five quarters ahead. 


\section{TABLE 2}

PSEUDO OUT- OF-SAMPLE FORECAST EVALUATION OF CHANGES IN CHILE'S RER PREDICTIVE VARIABLE: EXPORTS TO ASSETS RATIO (XA)

\begin{tabular}{|c|c|c|c|c|c|c|c|c|}
\hline (1) & (2) & (3) & (4) & (5) & (6) & (7) & (8) & (9) \\
\hline \multicolumn{9}{|c|}{$\begin{array}{l}\text { Panel 1: Estimation Window of Size: R-k= 65-k } \\
\text { Predictive Horizon in Quarters }\end{array}$} \\
\hline Benchmark & 1 & 2 & 3 & 4 & 5 & 6 & 7 & 8 \\
\hline RW & 1.21 & 1.11 & $1.97 * *$ & $2.55 * * *$ & $2.23 * *$ & $2.15^{* *}$ & $1.96^{* *}$ & $1.46^{*}$ \\
\hline RW-drift & 1.17 & 1.13 & $1.89^{* *}$ & $2.55^{* * *}$ & $2.49^{* * *}$ & $2.66^{* * *}$ & $2.66^{* * *}$ & $2.20 * *$ \\
\hline $\mathrm{AR}(1)$ & 0.47 & 0.66 & 1.18 & $1.48^{*}$ & $1.45^{*}$ & $1.55^{*}$ & $1.39^{*}$ & 0.88 \\
\hline \multicolumn{9}{|c|}{ Panel 2: Estimation Window of Size: R-k=35-k } \\
\hline Benchmark & 1 & 2 & 3 & 4 & 5 & 6 & 7 & 8 \\
\hline RW & 0.51 & -0.29 & 0.40 & 0.73 & 0.18 & -0.34 & -0.79 & -1.18 \\
\hline RW-drift & $1.30^{*}$ & 0.69 & $1.49^{*}$ & $1.89 * *$ & $1.43^{*}$ & 1.22 & 0.95 & 0.34 \\
\hline $\operatorname{AR}(1)$ & 0.81 & 0.50 & 0.80 & $1.35^{*}$ & 1.01 & 0.13 & -0.43 & -0.55 \\
\hline
\end{tabular}

Notes: $*$ Rejection at $10 \%, * *$ Rejection at $5 \%, * * *$ Rejection at $1 \%$.

Pseudo out-of-sample means that the predictor is computed with information from the full sample.

We consider three different null models for the returns of the RER: a driftless random walk, a random walk with drift and an $\mathrm{AR}(1)$.

Alternative model is: $\ln \left(R E R \_t+k\right)-\ln \left(R E R \_t\right)=a+b * \ln \left(Z \_t\right)+u \_t$

$\mathrm{Z}$ is Exports to Assets ratio (XA), $\mathrm{k}$ denotes the predictive horizon.

Updating scheme of the parameter estimates is done via rolling OLS.

Panel 1 considers a rolling window of size $\mathrm{R}=65-\mathrm{k}$ for estimation of the parameters. Panel 2 considers $\mathrm{R}=35-\mathrm{k}$.

Total number of observations is $91-\mathrm{k}$.

We report t-type statistics from tests by Diebold and Mariano (1995) and West (1996), and Clark and West $(2006,2007)$.

HAC estimation is computed according to Newey and West (1987) with optimal lag selection based upon Newey and West (1994).

Quarterly data from 1983:1 to 2005:4.

Source: Author's calculations.

Table 2 shows results for predictability when the predictor is the exports to assets ratio, which is one of the NXAP vector components. We observe similar results to those of Table 1: Panel 1 shows statistically significant evidence of predictability for several horizons beyond two quarters ahead and Panel 2 shows no evidence of predictability against the driftless random walk, evidence of predictability against the random walk with drift for three to five quarters ahead and evidence of predictability against the simple AR(1) only for four quarters ahead. These results are quite consistent with those of Table 1. 
TABLE 3

PSEUDO OUT- OF-SAMPLE FORECAST EVALUATION OF CHANGES IN CHILE'S RER PREDICTIVE VARIABLE: ASSETS TO LIABILITIES RATIO (AL)

\begin{tabular}{|c|c|c|c|c|c|c|c|c|}
\hline (1) & (2) & (3) & (4) & (5) & $(6)$ & (7) & (8) & (9) \\
\hline \multicolumn{9}{|c|}{$\begin{array}{l}\text { Panel 1: Estimation Window of Size: } \mathrm{R}-\mathrm{k}=65-\mathrm{k} \\
\text { Predictive Horizon in Quarters }\end{array}$} \\
\hline Benchmark & 1 & 2 & 3 & 4 & 5 & 6 & 7 & 8 \\
\hline RW & 0.53 & 0.84 & $1.29 *$ & $1.50 *$ & $1.37^{*}$ & $1.86^{* *}$ & $1.89 * *$ & $1.49 *$ \\
\hline RW-drift & 0.46 & 0.97 & $1.54 *$ & $1.74 * *$ & $1.60^{*}$ & $2.06^{* *}$ & $1.97 * *$ & $1.79 * *$ \\
\hline $\mathrm{AR}(1)$ & 0.07 & 1.14 & $1.58^{*}$ & $1.45^{*}$ & 1.12 & $1.60^{*}$ & 1.19 & 0.59 \\
\hline \multicolumn{9}{|c|}{ Panel 2: Estimation Window of Size: $\mathrm{R}-\mathrm{k}=35-\mathrm{k}$} \\
\hline Benchmark & 1 & 2 & 3 & 4 & 5 & 6 & 7 & 8 \\
\hline RW & 0.23 & 0.46 & 0.73 & 1.15 & 1.01 & 0.87 & 0.76 & 0.57 \\
\hline RW-drift & $1.66^{* *}$ & $2.11 * *$ & $2.68 * * *$ & $3.16^{* * *}$ & $3.73^{* * *}$ & $4.06^{* * *}$ & $3.68 * * *$ & $3.47 * * *$ \\
\hline $\mathrm{AR}(1)$ & $1.63^{*}$ & $2.06^{* * *}$ & $2.01^{* *}$ & $3.51^{* * * *}$ & $3.83^{* * *}$ & $3.91 * * *$ & $3.62 * * *$ & $3.57 * * *$ \\
\hline
\end{tabular}

Notes: $*$ Rejection at $10 \%, * *$ Rejection at $5 \%, * * *$ Rejection at $1 \%$.

Pseudo out-of-sample means that the predictor is computed with information from the full sample. We consider three different null models for the changes of the RER: a driftless random walk, a random walk with drift and an $\operatorname{AR}(1)$.

Alternative model is: $\ln \left(R E R \_t+k\right)-\ln \left(R E R \_t\right)=a+b * \ln \left(Z \_t\right)+u \_t$.

$\mathrm{Z}$ is the Assets to Liabilities ratio (AL), $\mathrm{k}$ denotes the predictive horizon.

Updating scheme of the parameter estimates is done via rolling OLS.

Panel 1 considers a rolling window of size $\mathrm{R}=65-\mathrm{k}$ for estimation of the parameters. Panel 2 considers $\mathrm{R}=35-\mathrm{k}$.

Total number of observations is $91-\mathrm{k}$.

We report t-type statistics from tests by Diebold and Mariano (1995) and West (1996), and Clark and West $(2006,2007)$.

HAC estimation is computed according to Newey and West (1987) with optimal lag selection based upon Newey and West (1994).

Quarterly data from 1983:1 to 2005:4.

Source: Author's calculations.

When we explore the predictive ability of the assets to liabilities ratio, we see a somewhat different picture. Table 3's Panel 1 still shows statistically significant evidence of predictability for several horizons beyond two quarters ahead. Table 3's Panel 2, however, shows strong evidence of predictability against the random walk with drift for all horizons. Panel 2 also shows that the assets to liabilities ratio strongly outperforms the simple AR(1) for every horizon. Surprisingly, the driftless random walk cannot be outperformed for any horizon, although the t-statistics display the correct sign. Results from Panel 2 contrast sharply with those from Tables 1-2, in which there was scarce evidence of predictability when the estimation window was set at $\mathrm{R}-\mathrm{k}=35-\mathrm{k}$. 
We do not report tables for the pseudo out-of-sample exercises when the predictor is the exports to imports ratio $(x m)$. This is simply because there is nothing really to show. In other words, $x m$ is drastically outperformed by our three benchmarks over any single horizon in both exercises with $\mathrm{R}$ set at $\mathrm{R}=65$ and $\mathrm{R}=35^{15}$.

In the next subsection we explore whether the results presented here stand when an out-of-sample exercise is carried out.

\section{IV.2. Out-of-Sample Exercises}

In this subsection we present forecasting results corresponding to an out-ofsample exercise evaluating the ability of the variables NXAPR $, x m^{R}, x a^{R}$ and $a l^{R}$ to predict RER returns for several horizons. We recall that $\mathrm{NXAP}^{\mathrm{R}}, x m^{R}, x a^{R}$ and $a l^{R}$ are variables built similarly to NXAP, $x m, x a$ and $a l$, but in an quasi out-of-sample fashion. Unlike the construction of NXAP, $x m, x a$ and $a l$, in this case the cointegrating relationships and calculation of the principal component coefficients is based on information available at the moment of prediction. In other words, when the size of the estimation window is set to $\mathrm{R}-\mathrm{k}=35-\mathrm{k}$, we use information available only until 1991Q1 and when the size of the estimation window is set to R-k=65-k, we use information available only until 1999Q3. Therefore these are out-of-sample exercises in the sense that the information used for prediction does not contain observations used for evaluation. Consequently, these exercises are more stringent than those presented in the previous subsection.

As expected, statistics reported in Table 4 are, with only a couple of exceptions, lower than those reported in Table 1 . In fact, Panel 2 shows no statistically significant evidence of predictability whatsoever.

The striking result is provided in Table 4's Panel 1. Despite the fact that reported statistics are, in general, a little lower than those in Table 1's Panel 1, they offer statistically significant evidence of predictability for horizons beyond two quarters ahead. Over these horizons, our measure of external imbalances outperforms both versions of a random walk at the $10 \%, 5 \%$ or $1 \%$ significance level. Similarly, our model outperforms the AR(1) model for the same horizons at a significance level of at least $10 \%$.

Our robustness check, available upon request, shows that these results are indeed robust to small variations in the size of the estimation window R-k.

Table 5 shows forecasting results for an out-of-sample exercise evaluating the ability of the variables $x m^{R}, x a^{R}$ and $a l^{R}$ to predict RER returns over several horizons, when the size of the estimation window is set to $R-k=65-k$. The out-of-sample exercise confirms the main findings from the pseudo out-of-sample exercise. Panel 1 in Table 5 shows that the exports to imports ratio has no ability to predict Chile's RER. Panel 2 and 3 show t-statistics that are fairly similar to those obtained in the pseudo out-of-sample evaluation. Basically they confirm that both the exports to assets and the assets to liabilities ratios are able to predict Chile's RER over several horizons beyond

15 Tables are available upon request. 
TABLE 4

OUT-OF-SAMPLE FORECAST EVALUATION OF QUARTERLY CHANGES IN CHILE'S RER EXTERNAL IMBALANCES BASED ON GOURINCHAS AND REY'S VARIABLE (NXAPR)

\begin{tabular}{|c|c|c|c|c|c|c|c|c|}
\hline$(1)$ & (2) & (3) & (4) & $(5)$ & (6) & (7) & $(8)$ & (9) \\
\hline \multicolumn{9}{|c|}{$\begin{array}{l}\text { Panel 1: Estimation Window of Size: R-k=65-k } \\
\text { Predictive Horizon in Quarters }\end{array}$} \\
\hline Benchmark & 1 & 2 & 3 & 4 & 5 & 6 & 7 & 8 \\
\hline RW & 0.90 & 0.63 & $1.42 *$ & $2.36^{* *}$ & $2.05^{* *}$ & $1.97 * *$ & $2.06^{* *}$ & $1.34^{*}$ \\
\hline RW-drift & 0.82 & 0.64 & $1.53^{*}$ & $2.75^{* * * *}$ & $2.56 * * *$ & $2.77 * * *$ & $3.26 * * *$ & $2.43 * * *$ \\
\hline $\mathrm{AR}(1)$ & 0.23 & 0.51 & $1.34^{*}$ & $1.87 * *$ & $1.79 * *$ & $2.03 * *$ & $1.99 * *$ & $1.44^{*}$ \\
\hline \multicolumn{9}{|c|}{ Panel 2: Estimation Window of Size: $R-k=35-k$} \\
\hline Benchmark & 1 & 2 & 3 & 4 & 5 & 6 & 7 & 8 \\
\hline RW & -1.22 & -1.28 & -1.11 & -1.14 & -1.29 & -1.33 & -1.45 & -1.56 \\
\hline RW-drift & -1.78 & -0.67 & -0.55 & -0.54 & -0.80 & -0.55 & -0.14 & 0.06 \\
\hline $\mathrm{AR}(1)$ & -0.01 & -0.34 & -0.86 & 0.16 & 0.15 & -0.84 & -0.73 & 0.16 \\
\hline
\end{tabular}

Notes: $*$ Rejection at $10 \%$, **Rejection at $5 \%$, ***Rejection at $1 \%$.

We consider three different null models for the returns of the RER: a driftless random walk, a random walk with drift and an $\operatorname{AR}(1)$.

Each panel considers alternative models as follows: $\ln \left(R E R \_t+k\right)-\ln \left(R E R \_t\right)=a+b * \ln \left(Z \_t\right)+u \_t$. $\mathrm{Z}$ is a measure of external imbalances $\left(\mathrm{NXAP}^{\mathrm{R}}\right)$. $\mathrm{k}$ denotes the predictive horizon.

Updating scheme of the parameter estimates is done via rolling OLS.

We pick a rolling window of size 65-k in Panel 1 and of size 35-k in Panel 2 for estimation of the parameters.

Total number of observations is $91-\mathrm{k}$.

We report t-type statistics from tests by Diebold and Mariano (1995) and West (1996), and Clark and West $(2006,2007)$.

HAC estimation is computed according to Newey and West (1987) with optimal lag selection based upon Newey and West (1994).

Quarterly data from 1983:1 to 2005:4.

Source: Author's calculations.

two quarters. The hardest benchmark to beat is the AR(1) model. This is especially relevant for the exports to assets ratio, which posts t-statistics that are significant only when the predictive horizon is six quarters ahead. Nevertheless, some of the other t-statistics are nearly close to become significant.

Table 6 provides forecasting results for an out-of-sample exercise evaluating the ability of the variables $x m^{R}, x a^{R}$ and $a l^{R}$ to predict RER returns over several horizons, when the size of the estimation window is set to $\mathrm{R}-\mathrm{k}=35-\mathrm{k}$. Panel 1 in Table 6 confirms that the exports to imports ratio has no ability to predict Chile's RER, as we saw earlier with the pseudo out-of-sample exercise. Panel 2 show t-statistics that are relatively different to those obtained in the pseudo out-of-sample evaluation, but equally weak in terms of predictability. In fact, we find that the exports to assets ratio beats both variants of the random walk only when prediction is made for four quarters ahead. Furthermore, the AR(1) is never beaten. Finally, Panel 3 shows quite different results 
from those of the pseudo-out-of-sample exercise. Now, we see no RER predictability based upon the assets to liabilities ratio. We tend to believe that the small size of the sample is playing an important role for this result.

\section{TABLE 5}

OUT-OF-SAMPLE FORECAST EVALUATION OF QUARTERLY CHANGES IN CHILE'S RER COMPONENTS OF THE EXTERNAL IMBALANCES' VARIABLE

\begin{tabular}{|c|c|c|c|c|c|c|c|c|}
\hline (1) & (2) & (3) & (4) & (5) & (6) & (7) & (8) & (9) \\
\hline \multicolumn{9}{|c|}{$\begin{array}{c}\text { Panel 1: The Predictive Variable the Exports to Imports ratio (XM) } \\
\text { Predictive Horizon in Quarters }\end{array}$} \\
\hline Benchmark & 1 & 2 & 3 & 4 & 5 & 6 & 7 & 8 \\
\hline $\mathrm{RW}$ & -2.12 & -216 & -2.03 & -2.79 & -2.58 & -2.51 & -2.73 & -2.70 \\
\hline RW-drift & -2.14 & -1.36 & -1.20 & -2.11 & -2.13 & -2.01 & -2.08 & -2.48 \\
\hline $\mathrm{AR}(1)$ & -2.04 & -1.21 & -1.23 & -1.64 & -2.13 & -2.46 & -2.83 & -2.62 \\
\hline \multicolumn{9}{|c|}{$\begin{array}{l}\text { Panel 2: The Predictive Variable is the Exports to Assets ratio (XA) } \\
\text { Predictive Horizon in Quarters }\end{array}$} \\
\hline Benchmark & 1 & 2 & 3 & 4 & 5 & 6 & 7 & 8 \\
\hline RW & 1.19 & 1.10 & $1.87 * *$ & $2.38^{* *}$ & $2.16^{* *}$ & $2.11 * *$ & $1.95^{* *}$ & $1.54^{*}$ \\
\hline RW-drift & 1.16 & 1.12 & $1.83^{* *}$ & $2.43^{* * * *}$ & $2.43 * * *$ & $2.59^{* * *}$ & $2.60 * * *$ & $2.23 * *$ \\
\hline $\mathrm{AR}(1)$ & 0.38 & 0.57 & 1.00 & 1.23 & 1.26 & $1.34^{*}$ & 1.17 & 0.71 \\
\hline \multicolumn{9}{|c|}{$\begin{array}{l}\text { Panel 3: The Predictive Variable is the Assets to Liabilities ratio (AL) } \\
\text { Predictive Horizon in Quarters }\end{array}$} \\
\hline Benchmark & 1 & 2 & 3 & 4 & 5 & 6 & 7 & 8 \\
\hline RW & 0.54 & 0.85 & $1.31^{*}$ & $1.53^{*}$ & $1.40^{*}$ & $1.89^{* *}$ & $1.91 * *$ & $1.53^{*}$ \\
\hline RW-drift & 0.47 & 0.98 & $1.55^{*}$ & $1.75^{* *}$ & $1.62 *$ & $2.08^{* *}$ & $1.99 * *$ & $1.81 * *$ \\
\hline $\mathrm{AR}(1)$ & 0.08 & 1.14 & $1.58^{*}$ & $1.46^{*}$ & 1.13 & $1.60^{*}$ & 1.21 & 0.63 \\
\hline
\end{tabular}

Notes: *Rejection at $10 \%$, **Rejection at $5 \%$, ***Rejection at $1 \%$.

We consider three different null models for the returns of the RER: a driftless random walk, a random walk with drift and an $\mathrm{AR}(1)$.

Each Panel considers alternative models as follows: $\ln \left(R E R \_t+k\right)-\ln \left(R E R \_t\right)=a+b * \ln \left(Z \_t\right)+u \_t$. $\mathrm{Z}$ is the Exports to Imports ratio (XM) in Panel 1, the Exports to Assets ratio in Panel 2 and the Assets to Liabilities ratio in Panel 3.

Updating scheme of the parameter estimates is done via rolling OLS.

We pick a rolling window of size $65-\mathrm{k}$ for estimation of the parameters. $\mathrm{k}$ denotes the predictive horizon.

Total number of observations is $91-\mathrm{k}$.

We report t-type statistics from tests by Diebold and Mariano (1995) and West (1996), and Clark and West $(2006,2007)$.

HAC estimation is computed according to Newey and West (1987) with optimal lag selection based upon Newey and West (1994).

Quarterly data from 1983:1 to 2005:4.

Source: Author's calculations. 
TABLE 6

OUT-OF-SAMPLE FORECAST EVALUATION OF QUARTERLY CHANGES IN CHILE'S RER COMPONENTS OF THE EXTERNAL IMBALANCES' VARIABLE

\begin{tabular}{|c|c|c|c|c|c|c|c|c|}
\hline (1) & (2) & (3) & (4) & (5) & (6) & (7) & (8) & (9) \\
\hline \multicolumn{9}{|c|}{$\begin{array}{c}\text { Panel 1: The Predictive Variable the Exports to Imports ratio (XM) } \\
\text { Predictive Horizon in Quarters }\end{array}$} \\
\hline Benchmark & 1 & 2 & 3 & 4 & 5 & 6 & 7 & 8 \\
\hline RW & -1.85 & -1.13 & -0.72 & -1.15 & -1.18 & -1.14 & -0.90 & -0.93 \\
\hline RW-drift & -1.97 & -1.44 & -1.31 & -1.89 & -1.98 & -1.89 & -1.26 & -1.13 \\
\hline $\mathrm{AR}(1)$ & -1.34 & -0.88 & -1.43 & -1.27 & -1.09 & -1.75 & -1.51 & -0.90 \\
\hline \multicolumn{9}{|c|}{$\begin{array}{c}\text { Panel 2: The Predictive Variable is the Exports to Assets ratio (XA) } \\
\text { Predictive Horizon in Quarters }\end{array}$} \\
\hline Benchmark & 1 & 2 & 3 & 4 & 5 & 6 & 7 & 8 \\
\hline RW & 0.58 & 0.52 & 1.27 & $1.43^{*}$ & 1.18 & 1.01 & 0.59 & 0.09 \\
\hline RW-drift & 1.08 & 0.94 & $1.43^{*}$ & $1.48^{*}$ & 1.20 & 1.10 & 0.89 & 0.50 \\
\hline $\mathrm{AR}(1)$ & 0.35 & 0.18 & 0.29 & 0.56 & 0.27 & -0.30 & -0.65 & -1.03 \\
\hline \multicolumn{9}{|c|}{$\begin{array}{c}\text { Panel 3: The Predictive Variable is the Assets to Liabilities ratio (AL) } \\
\text { Predictive Horizon in Quarters }\end{array}$} \\
\hline Benchmark & 1 & 2 & 3 & 4 & 5 & 6 & 7 & 8 \\
\hline RW & -0.70 & -0.66 & -0.55 & -0.71 & -0.65 & -1.07 & -1.76 & -2.06 \\
\hline RW-drift & -0.29 & -0.33 & -0.31 & -0.22 & 0.00 & -0.01 & -0.21 & -0.18 \\
\hline $\mathrm{AR}(1)$ & -0.32 & -0.71 & -1.30 & -1.15 & -0.68 & -1.19 & -1.54 & -1.38 \\
\hline
\end{tabular}

Notes: $*$ Rejection at $10 \%, * *$ Rejection at $5 \%, * * *$ Rejection at $1 \%$.

We consider three different null models for the returns of the RER: a driftless random walk, a random walk with drift and an $\mathrm{AR}(1)$.

Each Panel considers alternative models as follows: $\ln \left(R E R \_t+k\right)-\ln \left(R E R \_t\right)=a+b * \ln \left(Z \_t\right)+u \_t$. $\mathrm{Z}$ is the Exports to Imports ratio (XM) in Panel 1, the Exports to Assets ratio in Panel 2 and the Assets to Liabilities ratio in Panel 3.

Updating scheme of the parameter estimates is done via rolling OLS.

We pick a rolling window of size $35-\mathrm{k}$ for estimation of the parameters. $\mathrm{k}$ denotes the predictive horizon.

Total number of observations is $91-\mathrm{k}$.

We report t-type statistics from tests by Diebold and Mariano (1995) and West (1996), and Clark and West $(2006,2007)$.

HAC estimation is computed according to Newey and West (1987) with optimal lag selection based upon Newey and West (1994).

Quarterly data from 1983:1 to 2005:4.

Source: Author's calculations.

In short, this paper offers evidence of out-of-sample predictability of RER returns using a measure for external imbalances that considers the financial channel. Systematic evidence of predictability increases with the size of the estimation window. We also find that predictability is mainly driven by two components of our measure 
of external imbalances: the exports to assets ratio and the assets to liabilities ratio. Interestingly, no predictive ability is found when the export to imports ratio is used as a predictor.

\section{CONCLUSIONS}

Considerable literature argues that one should not expect much exchange rate predictability from fundamentals. Our objective in this paper is to evaluate the ability of an external imbalance measure to predict the real exchange rate in an emerging market economy. We use a variable that combines the trade and valuation channel for Chile, which is basically a linear combination of a set of variables constructed as in Gourinchas and Rey (2007).

The evidence in this paper indicates that an external imbalance measure contains information that is useful to predict Chile's real exchange rate for horizons of up to two years. Interestingly, evidence of predictability increases with the size of the window used to estimate the parameters of the models under evaluation. This could be because the external balance has turned out to be more relevant to the real exchange rate dynamics in recent years or because estimates of parameters become more precise as the estimation window size increases.

We also detect that predictability is mainly driven by two components of our external imbalance measure: the exports to assets ratio and the assets to liabilities ratio. Interestingly, the exports to imports ratio shows no predictive ability whatsoever.

Our results suggest that researchers and policymakers should pay more attention to external imbalances to understand the future dynamics of the real exchange rate. Further research should analyze more extensively the role that the external balance may have in predicting other variables, such as net export growth, returns of assets and liabilities. The comparison with other benchmarks, such as monetary models, may also prove useful.

\section{REFERENCES}

ALQUIST, R. and M.D. CHINN (2006). "Conventional and Unconventional Approaches to Exchange Rate Modeling and Assessment", NBER Working Paper 12481.

CHEN, Y. and K. ROGOFF (2003). "Commodity Currencies", Journal of International Economics 60 (1), pp. 133-160

CLARIDA, R., L. SARNO, M. TAYLOR, and G. VALENTE (2003). "The Out of Sample Success of Term Structure Models as Exchange Rate Predictors: A Step Beyond”, Journal of International Economics 60, pp. 61-83.

CLARIDA, R. and M. TAYLOR (1997). "The Term Structure of Forward Exchange Rates and the Forecastability of Spot Exchange Rates: Correcting the Errors", The Review of Economics and Statistics 79 (3), pp. 353-361.

CLARK, T. (2004). "Can Out-of-Sample Forecast Comparisons Help Prevent Overfitting?" Journal of Forecasting 23 (2).

CLARK, T. and K. WEST (2006). "Using Out-Of-Sample Mean Squared Prediction Errors to Test the Martingale Difference Hypothesis”, Journal of Econometrics 135 (1-2), pp. 155-186. 
CLARK, T. and K. D. WEST (2007). “Approximately normal tests for equal predictive accuracy in nested models", Journal of Econometrics 138 (1), pp. 291-311.

DE GREGORIO, J. (2005). "Global Imbalances and Exchange Rate Adjustment”, Policy Paper 15, Central Bank of Chile.

DIEBOLD, F. and R. MARIANO (1995). "Comparing Predictive Accuracy", Journal of Business \& Economic Statistics 13 (3), pp. 253-263.

ENGEL, C., N. MARK, and K. WEST (2007). "Exchange Rate Models Are Not as Bad as You Think" NBER Working Paper $\mathrm{N}^{\mathrm{o}} 13318$.

FLURY, B. (1988). "Common principal components and related multivariate models", New York: Wiley.

GOURINCHAS, P-O. and H. REY (2007). "International Financial Adjustment", Journal of Political Economy 115 (4), pp. 665-703.

INOUE, A. and L. KILIAN (2004). "In-Sample or Out-of-Sample Tests of Predictability: Which one Should We Use?" Econometric Reviews 23, pp. 371-402.

LANE, P. and G-M. MILESI-FERRETTI (2004). "The Transfer Problem Revisited: Net Foreign Assets and Real Exchange Rates", The Review of Economics and Statistics 86 (4), pp. 841-857.

LANE, P. and G-M. MILESI-FERRETTI (2005). "A Global Perspective on External Positions", WP/05/161.

LANE, P. and G-M. MILESI-FERRETTI (2007). "The external wealth of nations mark II: Revised and extended estimates of foreign assets and liabilities, 1970-2004", Journal of International Economics 73 (2), pp. 223-250.

LETTAU, M. and S. LUDVIGSON (2001). "Consumption, Aggregate Wealth and Expected Stock Returns", Journal of Finance 56 (3), pp. 815-849.

MARK, N. (1995). "Exchange Rates and Fundamentals: Evidence on Long-Horizon Predictability", American Economic Review 85, pp. 201-218.

MEESE, R. and K. ROGOFF (1983a). "Empirical Exchange Rate Models of the Seventies: Do They Fit Out-of-sample?" Journal of International Economics 14, pp. 3-24.

MEESE, R. and K. ROGOFF (1983b). "The out-of-sample failure of empirical exchange rate models: sampling error or misspecification?" in Exchange Rates and International Economics, ed. Frenkel, J.A. University of Chicago Press.

McCRACKEN, M. (2007). "Asymptotics for Out-of-Sample Tests of Granger Causality", Journal of Econometrics 140 (2), pp. 719-752.

NEWEY, W.K. and K.D. WEST (1987). “A Simple, Positive Semidefinite, Heteroskedasticity and Autocorrelation Consistent Covariance Matrix”, Econometrica 55 (3), pp. 703-708.

NEWEY, W.K. and K.D. WEST (1994). "Automatic Lag Selection in Covariance Matrix Estimation", Review of Economic Studies 61 (4), pp. 631-653.

PAN, H. (2006). "The Dynamics of External Adjustment: Evidence form Emerging Markets", Manuscript, Department of Economics, University of California, Davis.

PINCHEIRA, P. (2006). "Shrinkage Based Tests of the Martingale Difference Hypothesis", Working Paper $N^{\circ} 376$, Central Bank of Chile.

PISTELLI, A., J. SELAIVE and R. VALDES (2005). "Stocks, Flows and Valuation Effects of Foreign Assets and Liabilities: Do They Matter?" prepared for the Tenth Annual Conference of the Central Bank of Chile, Current Account and External Financing.

ROGOFF, K. and V. STAVRAKEVA (2008). "The Continuing Puzzle of Short-Horizon Exchange Rate Forecasting" manuscript, Harvard University, July 30. Also available as NBER working paper 14071.

SELAIVE, J. and V. TUESTA (2005). "Can Fluctuations in the Consumption-Wealth Ratio help to Predict Exchange Rates", Applied Financial Economics 16 (17), pp. 1251-1263.

STOCK, J. and M. WATSON (1993). "A Simple Estimator of Cointegrating Vectors in Higher Order Integrated Systems", Econometrica 61 (4), pp. 783-820.

STOCK, J. and M. WATSON (2002). "Forecasting Using Principal Components From a Large Number of Predictors", Journal of the American Statistical Association 97 (460), pp. 1167-1179.

TILLE, C. (2003). "The Impact of Exchange Rate Movements on U.S. Foreign Debt." Current Issues in Economics and Finance 9 (January), pp. 1-7. FRB New York.

WEST, K. (1996). “Asymptotic Inference about Predictive Ability”, Econometrica 64, pp. 1067-1084. 
